\title{
Experimental and Simulated Research On Decision Making For The Reliability of Technological Systems
}

\author{
Cezarina Adina TOFAN \\ Associate Professor, University of Pitesti, Faculty of Mechanics and Technology \\ Manufacturing and Industrial Management Department \\ cezarina_adina@yahoo.com
}

Received Date: March 03, $2017 \quad$ Accepted Date: March 7, 2017

Published Date: May 30, 2017

Abstract: Starting from the observation that, at the end of the first decade of the XXI century, after a prolonged and traumatic transition to the pluralist democracy and market economy, Romania longer has to recover significant differences from the other Member States of the European Union, together with the acquiring and the implementation of the principles and practices of sustainable development in the context of globalization. With all the realized progress in the last years, it is a fact that Romania still has an economy based on intensive consumption of resources, a society and an administration still in searching of a unitary vision and a natural capital affected by the risk of some damages that may become irreversible. Excellence level of the technological systems reliability is the result of interactions oriented from the design level towards the technological systems exploitation, including the maintenance of the economic regime that generating savings and projected revenue.

Keywords: Process of production, Reliability, Analysis of the processing, Decisional analysis, Adopting the decision, Cost of production, Decisional methods and techniques.

\section{JEL Classification: M11, M15, L61}

\section{INTRODUCTION}

The main way to increase the resource productivity is the structural adjustment of the economy by increasing the specific share of the products, processes and activities which used a small amount of energy and material resources, but generates a high added value.

As the research direction, it can be started from the system performance analysis in the context of the imposed mission - to ensure achievement within a technological process of the following elements:

$\checkmark$ Parts conform to the specifications;

$\checkmark$ Compliance with time limits, respectively productivity;

$\checkmark$ Compliance with the limits of cost.

In this regard, the operational capacity or effectiveness of a system (system effectiveness) is the ability to successfully perform a task in a given time when it operates under specified conditions. This property is dependent on both the system performance and reliability of its features. Industrial investment funds are linked by the perceived risks.

\section{METHOD}

The main descriptors that can take into account, when comparing the products and technological processes, refer to their quality, the advantages and shortcomings of existing conventional technologies, the 
quality - reliability correlation and the risk - quality - reliability one in the various operational technological systems and efficiency in a determined projection horizon.

\section{PROCESSING AND INTERPRETATION OF THE EXPERIMENTAL/SIMULATED DATA}

Numerous specific problems in the modern engineering find their solution after the analysis and numerical processing of the experimental data.

Statistical study of a population is realised by processing the obtained information from any number of items. Number of chosen items is called the selection volume. The larger the selection volume exists, the more real statistical processing results are.

In general, these values are presented in the form of correlation tables between the independent variables and a dependent variable by it. For example, in the two-dimensional case, if we denote by $x$ the independent variable and the dependent variable $y$, in an expressed relationship of dependency there is a relation:

$$
y=f(x)
$$

$\mathrm{n}$ values determined experimentally, may be presented in the table form (Table 1).

Table 1. Presentation of the experimental values

\begin{tabular}{|c|c|c|c|c|c|c|c|c|}
\hline $\mathrm{x}$ & $\mathrm{x}_{1}$ & $\mathrm{x}_{2}$ & $\mathrm{x}_{3}$ & $\ldots$ & $\mathrm{x}_{\mathrm{i}}$ & $\ldots$ & $\mathrm{x}_{\mathrm{n}-1}$ & $\mathrm{x}_{\mathrm{n}}$ \\
\hline $\mathrm{y}$ & $\mathrm{y}_{1}$ & $\mathrm{y}_{2}$ & $\mathrm{y}_{4}$ & $\ldots$ & $\mathrm{y}_{\mathrm{i}}$ & $\ldots$ & $\mathrm{y}_{\mathrm{n}-1}$ & $\mathrm{y}_{\mathrm{n}}$ \\
\hline
\end{tabular}

Values

$\mathrm{x}=\mathrm{x}_{1}, \mathrm{x}_{2}, \ldots, \mathrm{x}_{\mathrm{i}}, \ldots, \mathrm{x}_{\mathrm{n}}$ are called support points (nodes);

$\mathrm{y}=\mathrm{y}_{1}, \mathrm{y}_{2}, \ldots, \mathrm{y}_{\mathrm{i}}, \ldots, \mathrm{y}_{\mathrm{n}}$ are called support values (nodal).

Handling the presented data in the table form is difficult and not suitable for further processing using the tools of mathematical analysis (derivation, integration, etc.).

Therefore, it is arisen the question of determining the mathematical expression of dependence (relation 1).

\section{APPENDIX 1}

Simulation reliability and nonfiabilităţii for Cp and Cpk values of indices between 0.8 and 1.4

Table 1: Simulated values of reliability indices $\mathrm{Cp}$ and Cpk values between 0.8 and 1.4

\begin{tabular}{|c|c|c|c|c|}
\hline $\mathrm{T}$ & $\mathrm{R} 1(\mathrm{~T})$ & $\mathrm{R} 2(\mathrm{~T})$ & $\mathrm{R} 3(\mathrm{~T})$ & $\mathrm{R} 4(\mathrm{~T})$ \\
\hline 0 & 1.00000000 & 1.00000000 & 1.00000000 & 1.00000000 \\
\hline 10 & 0.00006345 & 0.23904443 & 0.92219933 & 0.98421890 \\
\hline 20 & 0.00000000 & 0.05714224 & 0.85045161 & 0.96868685 \\
\hline 30 & 0.00000000 & 0.01365953 & 0.78428591 & 0.95339991 \\
\hline 40 & 0.00000000 & 0.00326524 & 0.72326794 & 0.93835421 \\
\hline 50 & 0.00000000 & 0.00078054 & 0.66699721 & 0.92354595 \\
\hline 60 & 0.00000000 & 0.00018658 & 0.61510439 & 0.90897138 \\
\hline 70 & 0.00000000 & 0.00004460 & 0.56724886 & 0.89462682 \\
\hline 80 & 0.00000000 & 0.00001066 & 0.52311652 & 0.88050863 \\
\hline
\end{tabular}


Experimental and Simulated Research on Decision Making for the Reliability of Technological Systems

\begin{tabular}{|c|c|c|c|c|}
\hline 90 & 0.00000000 & 0.00000255 & 0.48241770 & 0.86661323 \\
\hline 100 & 0.00000000 & 0.00000061 & 0.44488528 & 0.85293713 \\
\hline 110 & 0.00000000 & 0.00000015 & 0.41027291 & 0.83947684 \\
\hline 120 & 0.00000000 & 0.00000003 & 0.37835341 & 0.82622898 \\
\hline 130 & 0.00000000 & 0.00000001 & 0.34891726 & 0.81319018 \\
\hline 140 & 0.00000000 & 0.00000000 & 0.32177126 & 0.80035714 \\
\hline 150 & 0.00000000 & 0.00000000 & 0.29673725 & 0.78772663 \\
\hline 160 & 0.00000000 & 0.00000000 & 0.27365089 & 0.77529544 \\
\hline 170 & 0.00000000 & 0.00000000 & 0.25236067 & 0.76306043 \\
\hline 180 & 0.00000000 & 0.00000000 & 0.23272684 & 0.75101850 \\
\hline 190 & 0.00000000 & 0.00000000 & 0.21462054 & 0.73916660 \\
\hline 200 & 0.00000000 & 0.00000000 & 0.19792292 & 0.72750174 \\
\hline 210 & 0.00000000 & 0.00000000 & 0.18252438 & 0.71602096 \\
\hline 220 & 0.00000000 & 0.00000000 & 0.16832386 & 0.70472137 \\
\hline 230 & 0.00000000 & 0.00000000 & 0.15522815 & 0.69360009 \\
\hline 240 & 0.00000000 & 0.00000000 & 0.14315130 & 0.68265432 \\
\hline 250 & 0.00000000 & 0.00000000 & 0.13201403 & 0.67188129 \\
\hline 260 & 1.00000000 & 1.00000000 & 1.00000000 & 1.00000000 \\
\hline 270 & 0.61149277 & 0.81219207 & 0.92219933 & 0.97141117 \\
\hline 280 & 0.37392340 & 0.65965596 & 0.85045161 & 0.94363966 \\
\hline \multicolumn{5}{|c|}{ Table 1 (continued) } \\
\hline $\mathrm{T}$ & $\mathrm{R} 1(\mathrm{~T})$ & $\mathrm{R} 2(\mathrm{~T})$ & $\mathrm{R} 3(\mathrm{~T})$ & $\mathrm{R} 4(\mathrm{~T})$ \\
\hline 290 & 0.22865145 & 0.53576734 & 0.78428591 & 0.91666211 \\
\hline 300 & 0.13981871 & 0.43514598 & 0.72326794 & 0.89045582 \\
\hline 310 & 0.08549813 & 0.35342212 & 0.66699721 & 0.86499873 \\
\hline 320 & 0.05228149 & 0.28704664 & 0.61510439 & 0.84026943 \\
\hline 330 & 0.03196975 & 0.23313700 & 0.56724886 & 0.81624711 \\
\hline 340 & 0.01954927 & 0.18935203 & 0.52311652 & 0.79291156 \\
\hline 350 & 0.01195424 & 0.15379021 & 0.48241770 & 0.77024315 \\
\hline 360 & 0.00730993 & 0.12490719 & 0.44488528 & 0.74822280 \\
\hline 370 & 0.00446997 & 0.10144863 & 0.41027291 & 0.72683199 \\
\hline 380 & 0.00273335 & 0.08239577 & 0.37835341 & 0.70605271 \\
\hline 390 & 0.00167143 & 0.06692119 & 0.34891726 & 0.68586749 \\
\hline 400 & 0.00102207 & 0.05435286 & 0.32177126 & 0.66625934 \\
\hline 410 & 0.00062499 & 0.04414496 & 0.29673725 & 0.64721177 \\
\hline 420 & 0.00038217 & 0.03585419 & 0.27365089 & 0.62870874 \\
\hline 430 & 0.00023370 & 0.02912049 & 0.25236067 & 0.61073470 \\
\hline 440 & 0.00014290 & 0.02365143 & 0.23272684 & 0.59327451 \\
\hline
\end{tabular}


Experimental and Simulated Research on Decision Making for the Reliability of Technological Systems

\begin{tabular}{|c|c|c|c|c|}
\hline 450 & 0.00008738 & 0.01920950 & 0.21462054 & 0.57631348 \\
\hline 460 & 0.00005344 & 0.01560181 & 0.19792292 & 0.55983736 \\
\hline 470 & 0.00003268 & 0.01267166 & 0.18252438 & 0.54383226 \\
\hline 480 & 0.00001998 & 0.01029182 & 0.16832386 & 0.52828474 \\
\hline 490 & 0.00001222 & 0.00835894 & 0.15522815 & 0.51318169 \\
\hline 500 & 0.00000747 & 0.00678906 & 0.14315130 & 0.49851043 \\
\hline 510 & 0.00000457 & 0.00551402 & 0.13201403 & 0.48425860 \\
\hline 520 & 0.00000279 & 0.00447845 & 0.12174325 & 0.47041422 \\
\hline 530 & 0.00000171 & 0.00363736 & 0.11227155 & 0.45696562 \\
\hline 540 & 0.00000104 & 0.00295423 & 0.10353675 & 0.44390151 \\
\hline 550 & 0.00000064 & 0.00239941 & 0.09548152 & 0.43121089 \\
\hline 560 & 0.00000039 & 0.00194878 & 0.08805299 & 0.41888307 \\
\hline 570 & 0.00000024 & 0.00158278 & 0.08120241 & 0.40690770 \\
\hline 580 & 0.00000015 & 0.00128552 & 0.07488481 & 0.39527468 \\
\hline 590 & 0.00000009 & 0.00104409 & 0.06905872 & 0.38397424 \\
\hline 600 & 0.00000005 & 0.00084800 & 0.06368591 & 0.37299687 \\
\hline 610 & 0.00000003 & 0.00068874 & 0.05873110 & 0.36233333 \\
\hline 620 & 0.00000002 & 0.00055939 & 0.05416178 & 0.35197464 \\
\hline 630 & 0.00000001 & 0.00045433 & 0.04994796 & 0.34191210 \\
\hline \multicolumn{5}{|c|}{ Table 1 (continued) } \\
\hline $\mathrm{T}$ & $\mathrm{R} 1(\mathrm{~T})$ & $\mathrm{R} 2(\mathrm{~T})$ & $\mathrm{R} 3(\mathrm{~T})$ & $\mathrm{R} 4(\mathrm{~T})$ \\
\hline 640 & 0.00000001 & 0.00036901 & 0.04606197 & 0.33213723 \\
\hline 650 & 0.00000000 & 0.00029970 & 0.04247832 & 0.32264182 \\
\hline 660 & 0.00000000 & 0.00024342 & 0.03917348 & 0.31341787 \\
\hline 670 & 0.00000000 & 0.00019770 & 0.03612576 & 0.30445762 \\
\hline 680 & 0.00000000 & 0.00016057 & 0.03331515 & 0.29575353 \\
\hline 690 & 0.00000000 & 0.00013041 & 0.03072321 & 0.28729828 \\
\hline 700 & 0.00000000 & 0.00010592 & 0.02833292 & 0.27908476 \\
\hline 710 & 0.00000000 & 0.00008603 & 0.02612860 & 0.27110606 \\
\hline 720 & 0.00000000 & 0.00006987 & 0.02409578 & 0.26335545 \\
\hline 730 & 0.00000000 & 0.00005675 & 0.02222111 & 0.25582643 \\
\hline 740 & 0.00000000 & 0.00004609 & 0.02049229 & 0.24851265 \\
\hline 750 & 0.00000000 & 0.00002006 & 0.01482142 & 0.22128953 \\
\hline 760 & 0.00000000 & 0.00001629 & 0.01366830 & 0.21496313 \\
\hline 770 & 0.00000000 & 0.00001323 & 0.01260490 & 0.20881758 \\
\hline 780 & 0.00000000 & 0.00001075 & 0.01162423 & 0.20284773 \\
\hline 790 & 0.00000000 & 0.00000873 & 0.01071986 & 0.19704855 \\
\hline 800 & 0.00000000 & 0.00000709 & 0.00988585 & 0.19141517 \\
\hline
\end{tabular}


Experimental and Simulated Research on Decision Making for the Reliability of Technological Systems

\begin{tabular}{|c|c|c|c|c|}
\hline 810 & 0.00000000 & 0.00000576 & 0.00911672 & 0.18594283 \\
\hline 820 & 0.00000000 & 0.00000468 & 0.00840743 & 0.18062694 \\
\hline 830 & 0.00000000 & 0.00000380 & 0.00775333 & 0.17546303 \\
\hline 840 & 0.00000000 & 0.00000308 & 0.00715012 & 0.17044675 \\
\hline 850 & 0.00000000 & 0.00000251 & 0.00659383 & 0.16557387 \\
\hline 860 & 0.00000000 & 0.00000203 & 0.00608083 & 0.16084031 \\
\hline 870 & 0.00000000 & 0.00000165 & 0.00560773 & 0.15624208 \\
\hline 880 & 0.00000000 & 0.00000134 & 0.00517145 & 0.15177530 \\
\hline 890 & 0.00000000 & 0.00000109 & 0.00476911 & 0.14743622 \\
\hline 900 & 0.00000000 & 0.00000089 & 0.00439807 & 0.14322119 \\
\hline 910 & 0.00000000 & 0.00000072 & 0.00405589 & 0.13912667 \\
\hline 920 & 0.00000000 & 0.00000058 & 0.00374034 & 0.13514920 \\
\hline 930 & 0.00000000 & 0.00000047 & 0.00344934 & 0.13128544 \\
\hline 940 & 0.00000000 & 0.00000039 & 0.00318098 & 0.12753214 \\
\hline 950 & 0.00000000 & 0.00000031 & 0.00293350 & 0.12388615 \\
\hline 960 & 0.00000000 & 0.00000025 & 0.00270527 & 0.12034439 \\
\hline 970 & 0.00000000 & 0.00000021 & 0.00249480 & 0.11690388 \\
\hline 980 & 0.00000000 & 0.00000017 & 0.00230070 & 0.11356174 \\
\hline 990 & 0.00000000 & 0.00000014 & 0.00212171 & 0.11031514 \\
\hline 1000 & 0.00000000 & 0.00000011 & 0.00195664 & 0.10716136 \\
\hline
\end{tabular}

This dependence can be determined on the basis of some equations:

- Rational. This type of equation is deducted theoretically, based on some laws or known strategies, following to determine the values of some constants that these expressions are contained, based on the experimental data.

- Empirical. This type of equation is deduced experimentally. The analytical representation of functional dependency between variables of this type of equation is done in two stages:

- Setting form of the dependency relationship;

- Determining the appropriate values of the parameters.

Experimental data processing, in the previously presented manner, appeal to the approximation theory. This area of mathematics provides practical admissible solutions where the exact methods are impossible to be approached.

The specific mathematical operations to the approximation theory are:

a. Interpolation. Interpolation means the mathematical operation to find a function, $\mathrm{F}(\mathrm{x})$, allowing for some values of $x$ in the range $\left[x_{1}, x_{2}\right]$, the estimation of the function values $f(x)$. 
A necessary condition to determine the interpolation function $\mathrm{F}(\mathrm{x})$ is coincident with the function $\mathrm{f}(\mathrm{x})$ in the nodal values:

$$
\left\{\begin{array}{l}
F\left(x_{1}\right)=y_{1} \\
F\left(x_{2}\right)=y_{2} \\
\cdots \\
F\left(x_{i}\right)=y_{i} \\
\cdots \\
F\left(x_{n}\right)=y_{n}
\end{array}\right.
$$

For this reason, the interpolation is recommended to be used in conditions in which:

- Experimental values are relatively accurate, unaffected by the significant error;

- The number of experimental values is relatively small - failure to comply with conditions leads to a complex relationships, difficult to use;

- The function $\mathrm{f}(\mathrm{x})$ is known, but its expression is complicated and/or very difficult to measure and manipulate.

b. Extrapolation. Extrapolation is the mathematical operation to find a function, $F(x)$, to estimate the values of the function $\mathrm{f}(\mathrm{x})$ for any value of $\mathrm{x}$, situated outside of the range where there are determined the nodal points, $\left(x<x_{1}\right) \cup\left(x_{n}<x\right)$.

c. Regression. As origin, this mathematical operation comes from statistics where it was developed for researching and describing the dependence between the random variables. This technique can be successfully applied to the study of the dependence of first form between two presented variables presented in a table form. Regression is the mathematical operation that determines the parameters values of a function drawn through the experimental points, from the condition of minimizing of the distance between the function $f(x)$ and the adopted model $\mathrm{F}(\mathrm{x})$ :

$$
d(f, F)=\left\{\int_{x_{1}}^{x_{n}}[f(x)-F(x)]^{2} \cdot d\right\}^{1 / 2}
$$

From a practical viewpoint, the relation 3 is not used only in cases where $f(x)$ is known, but because of its complexity is seeking a simpler expression and easier to use.

In most cases where we use the regression is not known expression of $\mathrm{f}(\mathrm{x})$. In these situations there are using an expression, less rigorous:

$$
d(f, F)=\left\{\sum_{i=1}^{n}\left[f\left(x_{i}\right)-F\left(x_{i}\right)\right]^{2}\right\}^{1 / 2}
$$

Relationship 4 called the principle of Gauss-Legendre, or the method of the least squares. For this reason, the regression is recommended to be used in conditions in which: 
- The experimental values are affected by significant error;

- The number of experimental values is relatively high and using the interpolation leads to obtain some complex relationships, difficult to use;

- The function $\mathrm{f}(\mathrm{x})$ is known, but its expression is complicated and/or very difficult to evaluate and manipulate.

After a series of measurements, such as those shown in Table 1. on the dependent variable $y$, for the different values of the independent variable $\mathrm{x}$, arises a question to find the functional dependency form, $\mathrm{F}(\mathrm{x})$ and the parameter values of this function.

Choice the function $\mathrm{F}(\mathrm{x})$ is essential for the success of using the regression method. Unfortunately, there is not a direct method to allow the specifying of the most suitable model of $\mathrm{F}(\mathrm{x})$.

If there is legitimate that we know a priori about the shape of the relationship between variables, then we use as the regression equation their mathematical expression. If there isn't such a theoretical basis, it proceeds to a qualitative analysis of the essence of phenomena and if it concludes that there may be a link between variables, to choose the best regression model, we can apply the following rules:

1. Experimental data are plotted. There are obtained a number of $\mathrm{n}$ points;

2. There are visual plotted a curve that approaches the most of the experimental points. Then there are effectively plotted, a corresponding curve, looking for to give equal weight to all scored points;

3. It is considered the appropriate functional form of the curve traced and then choose an equation which closely match to the empirical curve shape;

4. There are calculated the values of the parameters of this curve using the principle of Gauss-Legendre, according to relation 4; It considers the degree of concordance between the experimental points and the empirical curve obtained in step 3 by calculating the value of some concordance indicators;

5. If there are several potential mathematical models which shape could be modelled, for the arrangement on graphics of $n$ experimental points for each, in part, there are completed the 4 and 5 steps.

6. Depending on the values of the indicators of concordance and/or other theoretical or practical considerations, it is determined the most suitable model.

Type of the adopted mathematical model for $\mathrm{F}(\mathrm{x})$ determines the type of regression used to represent the experimental data.

Another method for approximating the curve is represented by the correlation coefficient.

The coefficient of correlation $r_{x, y}$ is used to measure the intensity of the linear relationship between two variables $\mathrm{x}$ and $\mathrm{y}$.

The coefficient of correlation is given by the relation:

$$
r_{x, y}=\frac{n \sum x-\sum x \cdot \sum y}{\sqrt{\left[n \sum x^{2}-\left(\sum x\right)^{2}\right]\left[n \sum y^{2}-\left(\sum y\right)^{2}\right]}}
$$

where $\mathrm{n}$ represents the number of experiments.

If the coefficient of correlation $r_{x, y^{\prime}}$ between the two analyzed values, is closed to 1 , then there is a linear 
functional dependence. If the coefficient of correlation $r_{x, y^{\prime}}$ is closer to 0 , then the connection between the two variables is lower.

Of course, in order to determine the coefficient of correlation, there is a series of programming environments which may be used successfully.

Graphical representation of data

Conclusions on the analyzed populations are taken from samples drawn from those populations, so by processing the collected data sets.

These data must be processed, meaning their compacting in a convenient form to reduce scattering of information contained by them, a scattering that may occur due because the large number of measurements or because the way of collecting, presentation and data storage.

Regardless of the care taken to obtain a data set by conducting of some independent measurements under the identical conditions, it can be produced random deviations of data from the true value, so measuring it becomes a random variable.

If the random variable is continuous in time or space it is a continuous random variable, and if it is represented by the discrete values it is a discrete random variable.

During repeated measurements of a variable under the identical measuring condition, each of the measured values tends to take a central value lying within the range. Central value and he values scattered around it can be determined from the probability density of measurement that describes the frequency with which it takes a certain value in a certain range of values.

Because their total gross form the obtained results from the measurements constitute a disordered crowd of values, for an easier interpretation, they are plotted.

There are several ways to plot the results obtained from measurements: histogram, frequency polygon, cumulative frequency chart.

All these are based on the so-called frequency table, which is actually an arrangement of data in a number of categories - classes, recording the number of measurements belonging to each class.

The variation interval of the results is divided into elementary intervals of the same length, recording the number of corresponding values for each such portion. For $n$ obtained results from the measurements there are calculated the difference between the maximum and the minimum.

Grouping interval length d is given by Sturges's formula:

$$
d=\frac{\Delta_{\max }-\Delta_{\min }}{1+3.22 \cdot \lg n}
$$

Because d is usually a decimal number, it is rounded to an integer number that is closest to the found value.

Histogram. (Figure 1) If $n_{i}$ represents the absolute frequency of the class $(i, i+1)$, the distribution of these frequencies can be realised in a system of rectangular axes in which a rectangle has the base the class $(\mathrm{i}, \mathrm{i}+1)$ and the proportional area with the absolute frequency $\mathrm{n}_{\mathrm{i}}$. The histogram is allowed to view the variable trend and density. 
If the absolute frequencies are too high, so uncomfortable to plot, there are calculated the relative frequencies:

$$
\mathbf{f}_{\mathbf{i}}=\frac{\mathbf{n}_{\mathbf{i}}}{\mathbf{n}}
$$

$\mathrm{n}_{\mathrm{i}}$ - absolute frequency corresponding to the class (frequency class number);

$\mathrm{f}_{\mathrm{i}}$ - relative frequency;

$\mathrm{n}$ - selection volume (total number of observations).



Fig1. Histogram

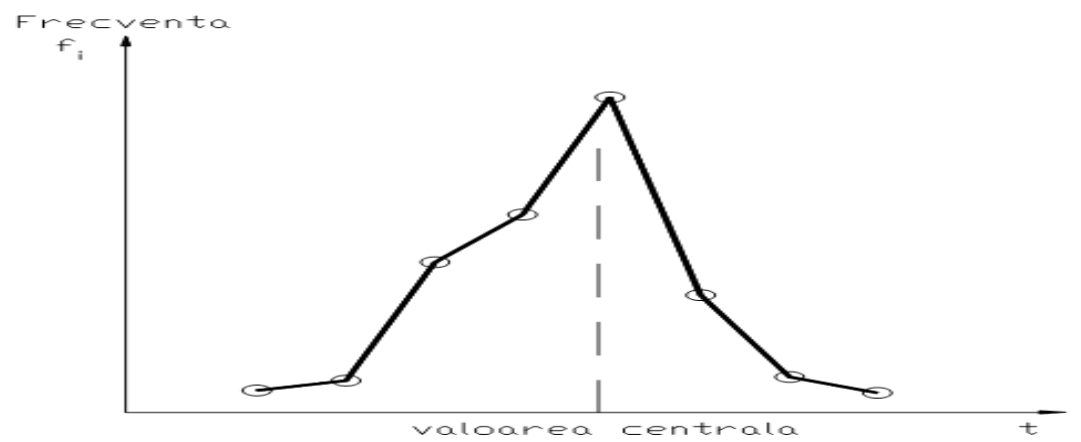

Fig2. Frequency Polygon

Frequency polygon (Figure.2) is obtained by joining through the line segments the middle of upper bases of the rectangles that forming absolute or relative frequency histogram. Cumulative frequency graph (Figure.3) expresses the relationship between the upper limit of classes studied $x i$ and cumulative frequency $F(x i)$ of the respective classes. It is obtained representing points $\mathrm{Ni}(\mathrm{i}, \mathrm{fk}), \mathrm{cu} \mathrm{k}=1, \ldots, \mathrm{i}$ in a rectangular coordinate system.



Fig3. Cumulative frequency graph 
Experimental and Simulated Research on Decision Making for the Reliability of Technological Systems

It is determined the total range of variation of the measured characteristics and they are divided into classes. The question is the number of classes and their limits. Using too little or too much of classes can adversely influence the subsequent analysis. For $n$ small, the number of classes should be chosen convenient so that $n_{i} 5$ for at least one interval. For n 40, the number of classes can be calculated with the equation:

$$
k=1.87 \cdot(n-1)^{0.40}+1
$$

By examining the histogram / frequency polygon can draw conclusions on the distribution of the measured variable, the central value and the dispersion of measurement results ${ }^{1}$.

\section{RESULTS}

\section{Case study on reliability estimation of technological processes}

In Table 1 are presented centralized the capability indices used to simulate the correlation capability - reliability of the technological processes.

Table 2. Centralization of the capability indices of the technological processes

\begin{tabular}{|c|c|c|}
\hline Capability index & Symbol & Relations of calculating \\
\hline Potentiality index & $\mathrm{C}_{\mathrm{p}}$ & ITS/INT; $\left(\mathrm{T}_{\mathrm{s}}-\mathrm{T}_{\mathrm{i}}\right) / 6 \mathrm{~s}$ \\
\hline & & $\min \left\{\mathrm{C}_{\mathrm{pkinf}}, \mathrm{C}_{\text {pksup }}\right\}$ \\
Capability index & $\mathrm{C}_{\mathrm{pk}}$ & $\mathrm{C}_{\mathrm{pkinf}}=\left|\mathrm{z}_{\text {inf }}\right| / 3, \mathrm{z}_{\text {inf }}=\left(\mathrm{T}_{\mathrm{i}}-\bar{x}\right) / \mathrm{s}$ \\
& & $\mathrm{C}_{\mathrm{pksup}}=\left|\mathrm{z}_{\text {sup }}\right| / 3, \mathrm{z}_{\text {sup }}=\left(\mathrm{T}_{\mathrm{s}}-\bar{x}\right) / \mathrm{s}$ \\
\hline
\end{tabular}

Table 2: Simulated values of non-reliability for values of the Cp and Cpk indices ranging from 0.8 and 1

\begin{tabular}{|c|c|c|c|c|}
\hline $\mathrm{T}$ & $\mathrm{F} 1(\mathrm{~T})$ & $\mathrm{F} 2(\mathrm{~T})$ & $\mathrm{F} 3(\mathrm{~T})$ & $\mathrm{F} 4(\mathrm{~T})$ \\
\hline 0 & 0.00000000 & 0.00000000 & 0.00000000 & 0.00000000 \\
\hline 10 & 0.38850723 & 0.18780793 & 0.07780067 & 0.02858883 \\
\hline 20 & 0.62607660 & 0.34034404 & 0.14954839 & 0.05636034 \\
\hline 30 & 0.77134855 & 0.46423266 & 0.21571409 & 0.08333789 \\
\hline 40 & 0.86018129 & 0.56485402 & 0.27673206 & 0.10954418 \\
\hline 50 & 0.91450187 & 0.64657788 & 0.33300279 & 0.13500127 \\
\hline 60 & 0.94771851 & 0.71295336 & 0.38489561 & 0.15973057 \\
\hline 70 & 0.96803025 & 0.76686300 & 0.43275114 & 0.18375289 \\
\hline 80 & 0.98045073 & 0.81064797 & 0.47688348 & 0.20708844 \\
\hline 90 & 0.98804576 & 0.84620979 & 0.51758230 & 0.22975685 \\
\hline 100 & 0.99269007 & 0.87509281 & 0.55511472 & 0.25177720 \\
\hline 110 & 0.99553003 & 0.89855137 & 0.58972709 & 0.27316801 \\
\hline 120 & 0.99726665 & 0.91760423 & 0.62164659 & 0.29394729 \\
\hline 130 & 0.99832857 & 0.93307881 & 0.65108274 & 0.31413251 \\
\hline 140 & 0.99897793 & 0.94564714 & 0.67822874 & 0.33374066 \\
\hline 150 & 0.99937501 & 0.95585504 & 0.70326275 & 0.35278823 \\
\hline
\end{tabular}

1. Tofan C.A., Imbunatatirea calitatii si fiabilitatii sistemelor tehnologice de presare la rece prin proiectare asistata si simulare pe calculator, "Alma Mater" Publishing House, Sibiu, 2012. 
Experimental and Simulated Research on Decision Making for the Reliability of Technological Systems

\begin{tabular}{|c|c|c|c|c|}
\hline 160 & 0.99961783 & 0.96414581 & 0.72634911 & 0.37129126 \\
\hline 170 & 0.99976630 & 0.97087951 & 0.74763933 & 0.38926530 \\
\hline 180 & 0.99985710 & 0.97634857 & 0.76727316 & 0.40672549 \\
\hline 190 & 0.99991262 & 0.98079050 & 0.78537946 & 0.42368652 \\
\hline 200 & 0.99994656 & 0.98439819 & 0.80207708 & 0.44016264 \\
\hline 210 & 0.99996732 & 0.98732834 & 0.81747562 & 0.45616774 \\
\hline 220 & 0.99998002 & 0.98970818 & 0.83167614 & 0.47171526 \\
\hline 230 & 0.99998778 & 0.99164106 & 0.84477185 & 0.48681831 \\
\hline 240 & 0.99999253 & 0.99321094 & 0.85684870 & 0.50148957 \\
\hline 250 & 0.99999543 & 0.99448598 & 0.86798597 & 0.51574140 \\
\hline 260 & 0.99999721 & 0.99552155 & 0.87825675 & 0.52958578 \\
\hline 270 & 0.99999829 & 0.99636264 & 0.88772845 & 0.54303438 \\
\hline 280 & 0.99999896 & 0.99704577 & 0.89646325 & 0.55609849 \\
\hline 290 & 0.99999936 & 0.99760059 & 0.90451848 & 0.56878911 \\
\hline 300 & 0.99999961 & 0.99805122 & 0.91194701 & 0.58111693 \\
\hline \multicolumn{5}{|c|}{ Table 2 (continued) } \\
\hline $\mathrm{T}$ & $\mathrm{F} 1(\mathrm{~T})$ & $\mathrm{F} 2(\mathrm{~T})$ & $\mathrm{F} 3(\mathrm{~T})$ & $\mathrm{F} 4(\mathrm{~T})$ \\
\hline 310 & 0.99999976 & 0.99841722 & 0.91879759 & 0.59309230 \\
\hline 320 & 0.99999985 & 0.99871448 & 0.92511519 & 0.60472532 \\
\hline 330 & 0.99999991 & 0.99895591 & 0.93094128 & 0.61602576 \\
\hline 340 & 0.99999995 & 0.99915200 & 0.93631409 & 0.62700313 \\
\hline 350 & 0.99999997 & 0.99931126 & 0.94126890 & 0.63766667 \\
\hline 360 & 0.99999998 & 0.99944061 & 0.94583822 & 0.64802536 \\
\hline 370 & 0.99999999 & 0.99954567 & 0.95005204 & 0.65808790 \\
\hline 380 & 0.99999999 & 0.99963099 & 0.95393803 & 0.66786277 \\
\hline 390 & 1.00000000 & 0.99970030 & 0.95752168 & 0.67735818 \\
\hline 400 & 1.00000000 & 0.99975658 & 0.96082652 & 0.68658213 \\
\hline 410 & 1.00000000 & 0.99980230 & 0.96387424 & 0.69554238 \\
\hline 420 & 1.00000000 & 0.99983943 & 0.96668485 & 0.70424647 \\
\hline 430 & 1.00000000 & 0.99986959 & 0.96927679 & 0.71270172 \\
\hline 440 & 1.00000000 & 0.99989408 & 0.97166708 & 0.72091524 \\
\hline 450 & 1.00000000 & 0.99991397 & 0.97387140 & 0.72889394 \\
\hline 460 & 1.00000000 & 0.99993013 & 0.97590422 & 0.73664455 \\
\hline 470 & 1.00000000 & 0.99994325 & 0.97777889 & 0.74417357 \\
\hline 480 & 1.00000000 & 0.99995391 & 0.97950771 & 0.75148735 \\
\hline 490 & 1.00000000 & 0.99996256 & 0.98110202 & 0.75859204 \\
\hline 500 & 1.00000000 & 0.99996960 & 0.98257229 & 0.76549361 \\
\hline 510 & 1.00000000 & 0.99997531 & 0.98392818 & 0.77219787 \\
\hline
\end{tabular}


Experimental and Simulated Research on Decision Making for the Reliability of Technological Systems

\begin{tabular}{|c|c|c|c|c|}
\hline 520 & 1.00000000 & 0.99997994 & 0.98517858 & 0.77871047 \\
\hline 530 & 1.00000000 & 0.99998371 & 0.98633170 & 0.78503687 \\
\hline 540 & 1.00000000 & 0.99998677 & 0.98739510 & 0.79118242 \\
\hline 550 & 1.00000000 & 0.99998925 & 0.98837577 & 0.79715227 \\
\hline 560 & 1.00000000 & 0.99999127 & 0.98928014 & 0.80295145 \\
\hline 570 & 1.00000000 & 0.99999291 & 0.99011415 & 0.80858483 \\
\hline 580 & 1.00000000 & 0.99999424 & 0.99088328 & 0.81405717 \\
\hline 590 & 1.00000000 & 0.99999532 & 0.99159257 & 0.81937306 \\
\hline 600 & 1.00000000 & 0.99999620 & 0.99224667 & 0.82453697 \\
\hline 610 & 1.00000000 & 0.99999692 & 0.99284988 & 0.82955325 \\
\hline 620 & 1.00000000 & 0.99999749 & 0.99340617 & 0.83442613 \\
\hline 630 & 1.00000000 & 0.99999797 & 0.99391917 & 0.83915969 \\
\hline 640 & 1.00000000 & 0.99999835 & 0.99439227 & 0.84375792 \\
\hline 710 & 1.00000000 & 0.99999961 & 0.99681902 & 0.87246786 \\
\hline 720 & 1.00000000 & 0.99999969 & 0.99706650 & 0.87611385 \\
\hline \multicolumn{5}{|c|}{ Table 2 (continued) } \\
\hline $\mathrm{T}$ & $\mathrm{F} 1(\mathrm{~T})$ & $\mathrm{F} 2(\mathrm{~T})$ & $\mathrm{F} 3(\mathrm{~T})$ & $\mathrm{F} 4(\mathrm{~T})$ \\
\hline 730 & 1.00000000 & 0.99999975 & 0.99729473 & 0.87965561 \\
\hline 740 & 1.00000000 & 0.99999979 & 0.99750520 & 0.88309612 \\
\hline 750 & 1.00000000 & 0.99999983 & 0.99769930 & 0.88643826 \\
\hline 760 & 1.00000000 & 0.99999986 & 0.99787829 & 0.88968486 \\
\hline 770 & 1.00000000 & 0.99999989 & 0.99804336 & 0.89283864 \\
\hline 780 & 1.00000000 & 0.99999991 & 0.99819559 & 0.89590226 \\
\hline 790 & 1.00000000 & 0.99999993 & 0.99833598 & 0.89887829 \\
\hline 800 & 1.00000000 & 0.99999994 & 0.99846544 & 0.90176924 \\
\hline 810 & 1.00000000 & 0.99999995 & 0.99858483 & 0.90457754 \\
\hline 820 & 1.00000000 & 0.99999996 & 0.99869493 & 0.90730556 \\
\hline 830 & 1.00000000 & 0.99999997 & 0.99879646 & 0.90995558 \\
\hline 840 & 1.00000000 & 0.99999997 & 0.99889010 & 0.91252985 \\
\hline 850 & 1.00000000 & 0.99999998 & 0.99897645 & 0.91503052 \\
\hline 860 & 1.00000000 & 0.99999998 & 0.99905608 & 0.91745970 \\
\hline 870 & 1.00000000 & 0.99999999 & 0.99912952 & 0.91981943 \\
\hline 880 & 1.00000000 & 0.99999999 & 0.99919725 & 0.92211170 \\
\hline 890 & 1.00000000 & 0.99999999 & 0.99925970 & 0.92433843 \\
\hline 900 & 1.00000000 & 0.99999999 & 0.99931730 & 0.92650151 \\
\hline 910 & 1.00000000 & 0.99999999 & 0.99937041 & 0.92860274 \\
\hline 920 & 1.00000000 & 1.00000000 & 0.99941939 & 0.93064391 \\
\hline
\end{tabular}


Experimental and Simulated Research on Decision Making for the Reliability of Technological Systems

\begin{tabular}{|c|l|l|l|l|}
\hline 930 & 1.00000000 & 1.00000000 & 0.99946456 & 0.93262672 \\
\hline 940 & 1.00000000 & 1.00000000 & 0.99950622 & 0.93455284 \\
\hline 950 & 1.00000000 & 1.00000000 & 0.99954464 & 0.93642390 \\
\hline 960 & 1.00000000 & 1.00000000 & 0.99958007 & 0.93824146 \\
\hline 970 & 1.00000000 & 1.00000000 & 0.99961274 & 0.94000707 \\
\hline 980 & 1.00000000 & 1.00000000 & 0.99964287 & 0.94172219 \\
\hline 990 & 1.00000000 & 1.00000000 & 0.99967065 & 0.94338829 \\
\hline 1000 & 1.00000000 & 1.00000000 & 0.99969628 & 0.94500675 \\
\hline
\end{tabular}

Simulated the correlation capability - reliability is based on the generation of 3000 values. To calculate the capability indices there were used the relationships from the Table 2. Substituting the simulated values of the capability indices there is obtained the correlation capability - reliability - non-reliability of the technological processes.

Based on the data from Table 3 there were obtained the simulated values of reliability and non- reliability of the technological processes presented in Appendix 1.

Table 3 Average of the operational period

\begin{tabular}{|c|l|l|}
\hline $\mathrm{Cp}$ & $\mathrm{Cpk}$ & $\mathrm{p}$ \\
\hline 0.80 & 0.80 & 0.016395072 \\
\hline 0.90 & 0.90 & 0.006933948 \\
\hline 1.00 & 1.00 & 0.002699796 \\
\hline 1.10 & 1.10 & 0.000966848 \\
\hline 1.20 & 1.20 & 0.000318217 \\
\hline 1.33 & 1.33 & $6.60733 \mathrm{E}-05$ \\
\hline 1.40 & 1.40 & $2.66915 \mathrm{E}-05$ \\
\hline 1.50 & 1.50 & $6.79535 \mathrm{E}-06$ \\
\hline
\end{tabular}

Reliability, respective the non-reliability of the simulated technological processes for values of the capability index ranging from 0.8 and 1.33, are plotted in Figure .4 and Figure .5 .

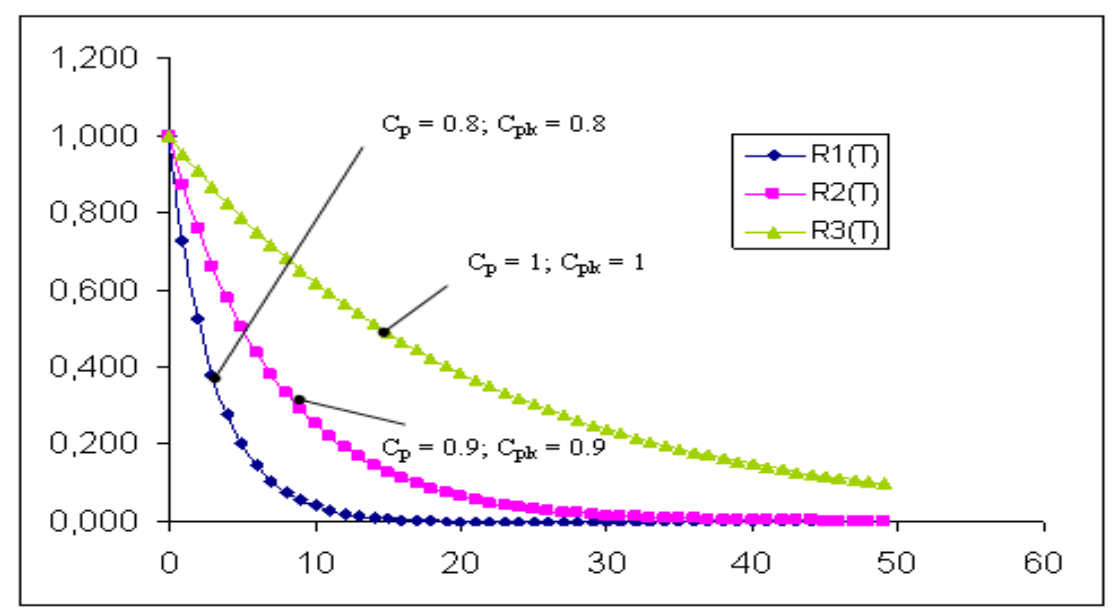

Fig4. Reliability for values of the Cp and Cpk indices ranging from 0.8 and 1 


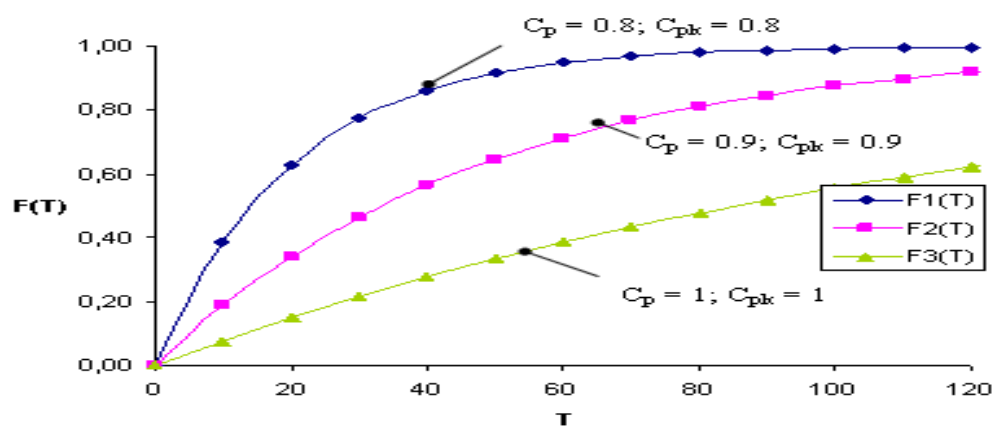

Fig5. Non-reliability for values of the $\mathrm{Cp}$ and Cpk indices ranging from 0.8 and 1

It is noted that for $\mathrm{C}_{\mathrm{p}}=0.8$ and $\mathrm{C}_{\mathrm{pk}}=0.8$, the reliability of the technological processes records a sharp decline.

The reliability, respective the non-reliability of the simulated technological process for values of the capability index ranging from 0.8 and 1.33, are plotted in Figure 6 and Figure 7.

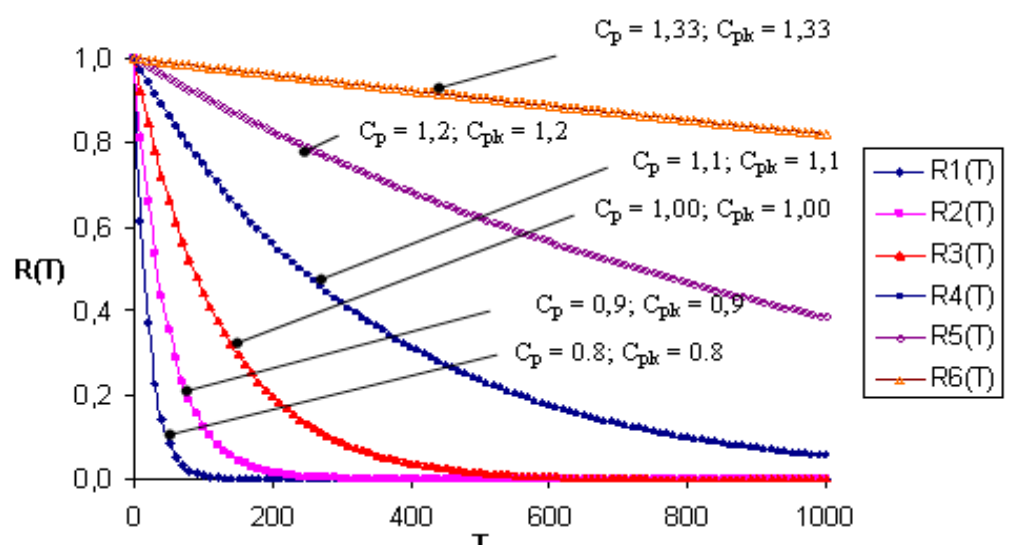

Fig6. Reliability for values of the $\mathrm{Cp}$ and $\mathrm{Cpk}$ indices ranging from 0.8 and 1.33



Fig7. Non-reliability for values of the Cp and Cpk indices ranging from 0.8 and 1.33 
Based on the presented concepts on the progress of systems, a development direction is the achievement of some standard models of structural decomposition of the specific activities of some projects classes encompassing the processes for fixing the costs. It can achieve the specific software that would allow a detail and refinement of the planning of these types of projects, with obvious effects on the efficiency and quality of the projects. It can develop databases on technological systems and can identify and estimate the parameters of used statistical distributions and the reliability indicators for technological systems in our country.

\section{ConCLUSION}

The defining element of the national development strategies is to connect Romania to a new philosophy of development, own to the European Union and widely world shared - the sustainable development. We can say that the correct decisions for the products quality and processes are ranged between the concrete objectives for moving, within a reasonable and realistic time, at the development model generating high added value, propelled by interest in knowledge and innovation, oriented towards the continuous improvement of people's lives and their relationships in harmony with the natural environment.

\section{REFERENCES}

1. Bârsan-Pipu, N. - Controlul statistic al proceselor. Course Notes, Braşov 2002

2. Morariu, C. O., Păunescu, T. - Informatică aplicată în inginerie. Transilvania Universitaty of Braşov, 2004

3. Popescu, I., ş.a. - Fiabilitate. Bazele teoretice. Transilvania Universitaty of Braşov, 1993

4. Tofan C.A., Imbunatatirea calitatii si fiabilitatii sistemelor tehnologice de presare la rece prin proiectare asistata si simulare pe calculator, "Alma Mater" Publishing House, Sibiu, 2012

5. Strategia Naţională pentru Dezvoltare Durabila a României Orizonturi 2013-2020-2030, http://www. insse.ro/cms/files/IDDT\%202012/StategiaDD.pdf

Citation: Cezarina Adina TOFAN, "Experimental and Simulated Research on Decision Making for the Reliability of Technological Systems". American Research Journal of Business and Management; V3, I1; pp:1-15.

Copyright (C) 2017 Cezarina Adina TOFAN, This is an open access article distributed under the Creative Commons Attribution License, which permits unrestricted use, distribution, and reproduction in any medium, provided the original work is properly cited. 